\title{
THE HOMOGRAFT
}

\author{
By G. M. WybURN, F.R.S.Ed., D.Sc., M.B., F.R.F.P.S. \\ Department of Anatomy, University of Glasgow
}

The penalty of the structural specialization, implying the increasing complexity in molecular configurations that has given man and mammals top ranking in the animal order has been the diminution of the powers of tissue repair, and a specific molecular 'fingerprint' inimical to the molecular patterns of all other organisms.

In simple forms such as hydra, the animal can be cut into several pieces and each piece will regenerate into what is more or less a new organism. Crabs, lizards, and salamanders can regrow appendages-limbs and tails - so can the tadpole but not the adult frog, although if the nerve from another limb is transplanted into an amputation stump in a frog a new limb grows, as though the tissues were subsidized from the reserves of nerve growth potential(Singer, 1958). While it is unlikely that such experiments would be successful at mammalian level, there is always the hope that whatever the nature of the regenerative factor it might some day be possible to restore this lost capacity temporarily to mammalian tissues so that they can replace destroyed limbs and organs. Meanwhile, in man the skin, nerve fibre and connective tissues generally, including bone, repair the most readily and certain organs-liver, pancreas, salivary gland-can to some extent replace lost tissue, but there is a limit to our regenerative power, and extensive tissue loss cannot be made good. Thus, inevitably there is a long history of attempts to transplant tissues and organs from one individual to another of the same and of different species with sporadic claims of dramatic successes, unfortunately never repeated. This rigid specificity is a characteristic of the adult tissues, and embryonic tissues are more plastic. Larval chimeras can be formed in the frog, for instance, by grafting together different parts of different embryos and the composite organism behaves physiologically as one unit.

Loeb devoted his lifework to the study of tissue transplantation consummated in his book 'The Biological Basis of Individuality' (1945) and many of his theories and conclusions expressed in more modern terms are a good fit to those of today.
However, the real impetus for the attack on the homograft problem was a wartime by-product which has since grown steadily in depth and breadth. Nevertheless, despite the impressive volume of work and the contributions of fundamental biological significance such as 'actively acquired tolerance,' 'enhancement' and ' radiation chimeras' the homograft problem remains unsolved. The plastic surgeon or clinician still looks in vain for 'spare parts' and is little better off in this respect than he was before the great onslaught of research ten or so years ago.

The current concept of the homograft reaction is that of antigen and antibody (Gibson and Medawar, 1943). From time to time various parts and fractions of the cell have been indicted as the source of the tissue antigen including, inevitably, the Nucleic acids. It is, however, unlikely that antigenicity resides exclusively in any one cell substance or structure. DNA and RNA as the templates of the cellular proteins may well codify the molecular ' fingerprints' that stamp the tissue specificity.

The specificity of antigens is a property of the chemi al structure of the molecules and most good antigens are proteins. The specificity of the protein molecule 'Nature's noblest piece of architecture' depends on the combination and arrangement of the amino acids and their side groups in the polypeptide chains. Other chemical groupings such as the conjugate combines may also provide specific determinants. While the specificity of a tissue is not a single factor based on any one particular molecular pattern, it is unlikely that all the varieties of protein found in any one tissue or organ act as separate antigens. It is true that antibodies are not rigidly specific for the tissue or organ against which they have been prepared, but it is known that single antigens can produce a number of antibodies, some of which combine with a substance in another organ similar to but not identical in structure with the causal antigen.

In contrast to infection immunity, in homologous tissue immunity no circulating antibodies 
can be recovered from the bloodstream, although antisera can be prepared against heterologous tissues. In the homograft reaction the antibodies are formed in special lymphocytes-the plasma cells-initially at any rate found in the regional lymph nodes draining the lymph from the grafted area (Scothorne and McGregor, 1955) and one aspect of tissue immunity which has received little attention is the logistics of the immune reaction. Why, for instance, do the antibody-containing cells converge on the graft site and how do they get there? What is the method of attack once they are in position?

Up to the present there have been two main lines of attack on the homograft problem: ( $r$ ) the objective-the prevention of the host reaction to the homograft which in practice means the prevention of antibody formation; (2) the treatment of the homograft so that it will cease to act as an antigen or in some way be rendered invulnerable to antibody action.

In respect of (I) there are only two procedures which have been successful in producing a lasting tolerance to homografts:

(a) The now well-known ' activity acquired tolerance' following the injection of foreign tissue at or before birth, first demonstrated by Professor Medawar and his colleagues (Billingham, Brent and Medawar, 1953; 1956) and since repeated by them and others in a variety of animals. While such acquired tolerance is long lasting it is, of course, limited to homografts from the original donor or donor strain, and does not provide a working solution to the homograft problem.

A corollary of this kind of immunity with, however, a different cause and effect, is the much discussed 'enhancement.' The term was first used to describe the growth of tumour homografts which normally regress, after pretreatment of the host with doses of dead preparations of donor tissues (Snell, r952; Kaliss, 1955). Similar pretreatment is said to prolong the life of skin and ovarian homografts. One suggestion is that the pretreatment induces the formation of $a$ ' blocking' substance which will unite with the graft antigens and so prevent tissue antibody formation.

(b) Animals which have been heavily irradiated so that there is an almost complete destruction of the antibody forming cells will survive if injected with homologous or heterologous suspensions of bone marrow or splenic cells (Ford, Hamilton, Barnes and Loutit, 1956). In such radiation chimeras the grafted cells survive, multiply, and repopulate the bone marrow and lymph nodes, as has been confirmed by using marker cells distinguished by characteristic chromosomes. Skin grafts from the original donor of the grafted cells will survive in these radiation chimeras. While such procedures provide a rather desperate remed for the late stages of leukaemia or severe radiation

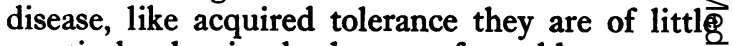
practical value in the homograft problem.

An interesting observation arising from such experiments is the onset of secondary disease? causing the death of a proportion of the radiation chimeras within 20 to 120 days after the initia treatment. Evidence is accumulating that this secondary disease is due to antibody formation by the donor tissue against recipient antigens (Barnes, Ford, Ilbery and Loutit, 1958) and todaythis antigen antibody reaction in reverse is attract: ing the attention of the pathologist.

Another method of treating the host which can claim to prolong the survival of homografts, is the administration of cortisone (Billingham, Krohn. and Medawar, 195 I). In the opinion of Scothorne (1956) cortisone acts by reducing the effectives antigenicity of the homograft, although how this is accomplished is not known.

\section{Pre-treatment of Grafts}

The aim of such treatment is to destroy the antigens while retaining the viability of the graft and this poses the question 'Is tissue antigenicity as built-in component of the living molecules of adult mammalian tissue which can only be neutralized by denaturation and so precluding any possibility of processing non-antigenic viable tiss out of normally antigenic substance?' While of the many methods of pretreatment of grafts freezing, culturing in vitro, and membrane pro tection merit mention, none of them has offered to the replacement surgeon a promise of lasting and successful homografts.

\section{Freezing}

Polge, Smith and Parkes (1949), first described the protective properties of glycerol against the 3 . biological effects of low temperature, in particularo the control of ice crystallization, and so introduced. an ideal method for the long term preservation of tissues. The preservation, unfortunately, also applies to the tissue antigens of a treated homograft, and although, for instance, frozen gonadab homografts may take and function for varying. periods of time, there is no suggestion that then immunological reaction evoked by the homograft is decreased by freezing it (Parkes, 1957). TheO same is true for frozen skin homografts.

\section{Tissue Culture}

Liver cells lose most of their enzymatic activity足 after prolonged culture, possibly from lack of substrate. Theoretically, therefore, there is the argument that isolated from all humoral in $\frac{0}{0}$ fluences even the nucleic acids might shed some of 
their finer shades of specificity to the extent of producing a neutral brand of protein molecule. If this were so, it would then be possible to have large scale synthetic plants producing cultured grafts of wanted tissues and organs. An effort has in fact been made to acclimatize host and homograft by growing the necessary tissue in culture medium to which has been added the serum from the prospective host. This has been done, for example, with the parathyroids (Galliard, I954). Similarly, the endocrines of infantile ratsthyroids, parathyroids, adrenals - have been explanted for periods of three or four months and then grafted into adult rats from which the corresponding gland has been removed. There is certainly evidence of an increased survival period during which such grafts appear to function, and thyroid grafts for example take up radioactive iodine, indicating they are elaborating their secretion. Although there are interesting possibilities in this type of experiment, on the whole the results have been equivocal and it cannot be said that tissue culture has provided the solution to the homograft problem. One of the more dramatic tissue culture experiments recently reported was the combination of the kidney cells of the mouse and the chicken to form a chimera kidney capable, it was said, of partial function.

Recent experiments (Algire, Weaver and Prehn, 1957) have shown that homograft tissue can be protected from host reaction if enclosed in Millipore filters with a porosity small enough to prevent transport of cells, but large enough to let through protein molecules. Such homografts survive in immune as well as non-immune hosts, indicating that they are protected against host antibodies, and according to Woodruff (1957) are not effectively antigenic. Such protected grafts are useful biological tools, but as they are nourished by diffusion only, they are of limited practical application.

Leob (1945) emphasised the variation in the behaviour of tissues and organs as homografts with regard to survival time and the histological and functional history of the graft. Through the work of Medawar, Billingham and their colleagues (1956), there is a very complete record of all aspects of the skin homograft, and to this has been added details of histochemical analyses, revascularization, and lymphatic regeneration (Scothorne, 1953a, 1953 b, 1958) and re-innervation (Hutchison, Tough and Wyburn, 1949; Adeymo and Wyburn, 1957).

The position with regard to the long term survival of homocrafts of endocrine glands is by no means clear (Rob, 1954). In a recent report, Coupland (1958) claims a Ioo per cent. survival of six-months-old intraocular homografts of chro- maffin and cortical adrenal cells. More long-term genetically controlled studies of endocrine grafts are required to provide sufficient data for a final verdict in respect of the different glands. At present it can be said that there is evidence, as far as the endocrines are concerned, that the homograft reaction is a variable factor determined by the species of animal used as donor and host, and the physiological conditions at the time of grafting.

Within the scope of one article it is only possible to deal in detail with the behaviour of a few kinds of homograft and subsequent remarks will be confined to those on which personal observations are available, namely cartilage, cornea, bone, and nerve.

While there may be some difference of opinion about the details of the histological fate of cartilage and corneal homografts, there is complete agreement that they are clinically a success and able to survive permanently as a functioning replacement of the relevant host tissue. They share a common denominator of cause and effect-an abundant ground substance of mucopolysaccharides and avascularity.

There is now ample evidence that cartilage homografts survive, probably permanently, both in man and in animals. This has been confirmed in man by Gibson, Davis and Curran (1958), who report the survival of human cartilage implants removed at intervals of from two weeks to two years and examined histologically and tested for viability by the uptake of ${ }^{35} \mathrm{~S}$ in vitro. Their material also includes 22-year-old cartilage graft inserted by Sir Harold Gillies. Craigmyle (1955, 1958) confirms long-term survival up to two years in rabbits (a relatively large proportion of the rabbit life span). Bacsich and Wyburn (1947, 1956) investigated the histology of short-term cartilage homografts in the guinea pig (up to three weeks) and found no evidence of any degenerative change either in the cells or the matrix. In these studies the host animals were given injections of ${ }^{35} \mathrm{~S}$, and autoradiographed sections of three-weeksold grafts showed a normal cellular uptake of the isotope. We feel convinced that the survival of cartilage and corneal homografts is an attribute of the mucoproteins of their ground substance. The major constituent of the cartilage matrix is the mucopolysaccharide-chondroitin sulphate. The uptake of ${ }^{35} \mathrm{~S}$ by healthy cartilagenous cells indicates an active turnover with a continuous cycle of break down and formation of chondroitin sulphate. This cycle presumably involves a depolymerization of high-grade molecules and the possible diffusion of the degraded non-antigenic molecules into the host tissue. The depolymerization also liberates chondrosamine which is made available for the nutrition of the tissues. 
Is the survival of these homografts merely because a successful ' take' is not vascularized ? Does the ground substance simply act like the Millipore membrane as a barrier to the penetration of antibody-containing cells? Are cartilage homografts in virtue of their ground substance non-antigenic ? Heterografts, although avascular, are destroyed by the immune reaction. Moreover, Craigmyle (1956) found that whereas there was considerable increase in the weight of regional lymph nodes with heterografts there was no significant change with homografts, indicating the absence of an antigenic stimulus. In the large number of cartilagenous homografts of all ages which we have examined over a number of years, there has never been any evidence of the host reaction in the form of the aggregation of lymphocytes around the graft, to be expected with the formation of antibody. The conclusion from present available evidence is thus that cartilage does not in fact exite a homograft reaction. It has been stated that it is the immunologically inert ground substance that confers survival value on cartilage homografts, and that deprived of this protection the cartilage cells die. We have found, however (Bacsich and Wyburn, 1955), that growing cartilage with a high cell content and little ground substance not only survives but shows active cell proliferation and deposition of ground substance. This is interpreted to imply that it is the active production of the mucopolysaccharides by the cells which gives protection against or prevents host reaction, rather than the quantitative characteristics of the tissue, although little is known concerning the chemical mechanism of this intracellular process. Nor do we know very much about the life span of normal chondrocytes, whether they are renewed from time to time, or last throughout the life of the cartilage, but it seems improbable that the graft chondrocytes could synthetise a chondroitin sulphate antigenic to the host tissue. In this respect it can therefore be argued that if there is 'replacement' it is not by host tissue, but by material elaborated by the native cells of the graft. There is some clinical evidence of the protective nature of the mucoproteins and their influence on both the local and general host reactions to living foreign elements. In 1936 , Nungster, Jourdonais, and Wolf reported that the simultaneous injection of gastric mucin and bacteria of low virulence into the peritoneal cavity increased the virulence of meninococci, streptococci, and staphylococci, by in some way or other affording them protection from the host reaction, and again there is the well known increased fatality rate associated with the presence of circulating capsular polysaccharides in the blood of patients with pneumococcal pneumonia.

Cartilage autografts are not readily available, so an important practical point is the storage anç preservation of homograft material. Unfortunately, glycerol does not protect cartilage from the्ठ lethal effects of freezing (Wyburn and Bacsich 1956; Curran and Gibson, 1956; Alexander r957). According to Smith (1954) 'the optimum rate of cooling for preserving the viability of anyo cell depends on conflicting factors. The occur-0 rence of thermal shock must be avoided withouten cooling so slowly as to prolong the harmful effects $\frac{1}{2}$ of concentrated salt solutions during the separationo of ice, or to allow the coagulation and loss of solubility of colloidal substances or any other form $\vec{P}$ of intracellular disorganisation.' There is a critical range of temperature in which this harmfun action occurs. If cells remain more than a few seconds within this critical range they are irre-3. versibly damaged (Lovelock, 1953). The pro-w tective action of glycerol in freezing is due to $a_{p}$ narrowing of this range of critical temperature (Lovelock, 1954). The eutectic temperature for $\bar{\omega}$ the mixture of salts and other substances within the cells determines the lower limit of the criticale range for any tissue. Obviously, the final storagetemperature must lie beyond the critical zone.

There are differences of opinion about the histo-⿳亠丷厂巾 logical progress of the corneal homograft, but $\mathrm{a}^{\supset}$ unanimous verdict concerning its clinical successe under proper conditions. Its behaviour as inco orthotopic homograft is therefore quite differe⿳亠丷⿵冂丶 from the skin homograft and whether, as is maintained by Maumenee (r953) its epithelium is finally replaced by host epithelium or not, a successful ' take' does not slough off leaving a raw@ area as it would if a homograft reaction were $\Rightarrow$ elicited with antibody-containing cells marshalled to the graft site and the invasion of its substance. It would be surprising if a delicate operation like corneal grafting, often dealing with unhealthy recipient tissue, could mark up Ioo per cent. 3 successes. The argument that, because of the in-ס; evitable odd failure or delayed clouding of a graft, corneal tissue is therefore antigenic surely qualifies as post hoc ergo propter hoc (Nelken Michaelson and Gurevitch, 1958). Again, the plea that theo avascularity of the clinical corneal graft is responsible for the absence of any homograft re-을. action is not valid. Intraocular grafts and heterologous corneal grafts readily become vascularized. Moreover, according to Craigmyle a subcutaneous 0 corneal graft elicits no response from the regionali lymph nodes.

If the clinical success of the corneal homografto were merely a fortuitous result of place and cir- $\frac{\pi}{\infty}$ cumstance, heterotopic grafts of whole cornea, not $\stackrel{\text { s }}{+}$ just the epithelium, should be destroyed.

Our personal observations have been made on ao음 large series of subcutaneous corneal homografts 


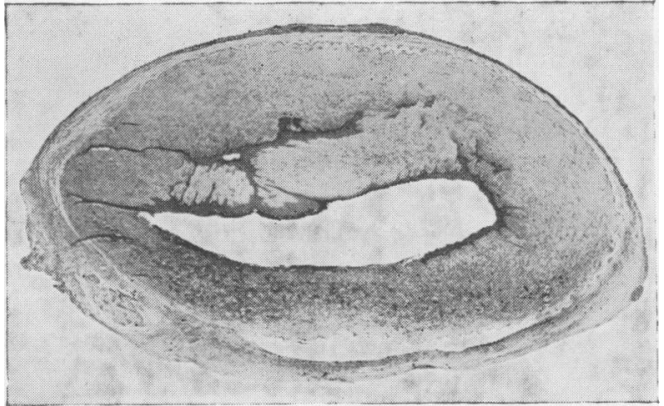

FIG. I.-A 2I-day-old cystic corneal homograft. $x$ i 8. Text Fig. 1.-After Sobel.

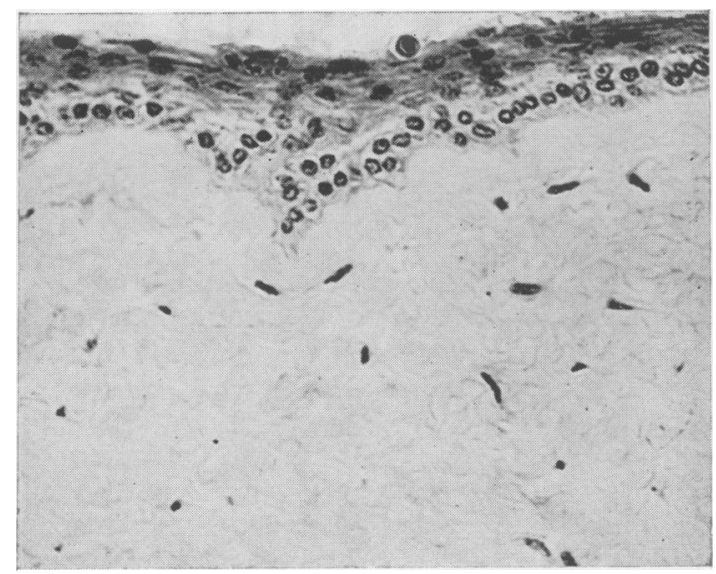

Fig. 2.-A 2 I-day-old cystic corneal homograft showing epithelium and ground substance. $x$ I35.

in the guinea pig, examined histologically, and tested for viability by the uptake of ${ }^{35} \mathrm{~S}$ from the host at intervals ranging from three weeks to five months (Bacsich and Wyburn, 1955, 1957). The experiments also included examination of second sets of corneal grafts from the same donor. Healthy viable grafts were recovered up to three months. After three months most of the grafts were absorbed, as indeed may happen to many soft tissue non-glandular autografts. The majority of the recovered grafts formed inverted cysts with a lining of intact corneal epithelium, Figs. I and 2). In the non-cystic grafts the epithelium had disappeared by three weeks, but there was no evidence of host reaction, and the ground substance was normal and viable. Cystic formation does not by itself confer protection from a host reaction, as the behaviour of skin homografts which form cysts when implanted subcutaneously is identical with that of orthotopic controls and after three weeks the epithelium has degenerated. The behaviour of the second set of homografts was no different from that of the first set, with no evidence of donor

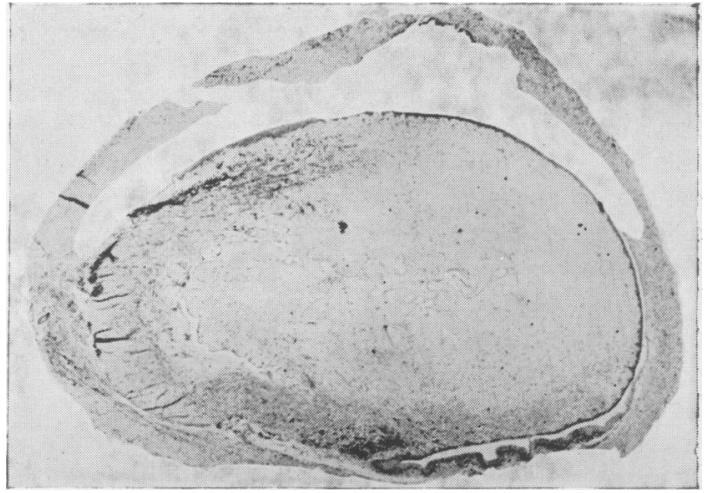

FIg. 3.-A 2I-day-old second-set cystic corneal homograft. $x$ I 8 .

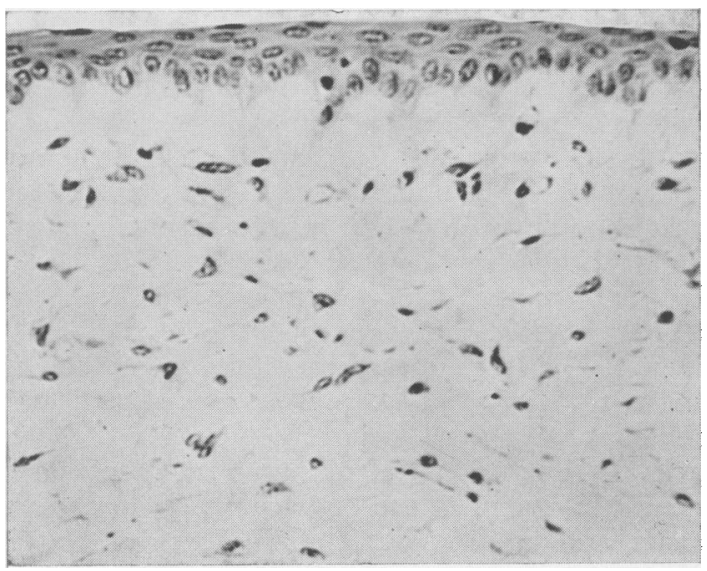

FIG. 4.-A 2I-day-old cystic second-set cystic corneal homograft showing epithelium and ground substance. $x$ I35.

recipient reaction, Figs. 3 and 4 . The mucopolysaccharides which form the bulk of the ground substance of cornea and cartilage have a low protein content and are predominantly carbohydrates. Antigenicity is not a 'sine qua non' of all the giant molecules of living substance. It is not unreasonable to suppose that the carbohydrate polymers are not individually specific, and they are in sufficient quantity in these tissues to confer neutrality.

As with cartilage, the question of the preservation of the cornea and an available 'bank' of material is of importance. Rob and Eastcott (1954) had successful corneal homografts with glyceroltreated material stored at $-79^{\circ} \mathrm{C}$. for a perfod oi months. The fact that such grafts remain transluscent is evidence of their viability, and this was further confirmed by the uptake of ${ }^{35} \mathrm{~S}$ from the host by grafts previously stored in this way (Bacsich and Wyburn, 1954). On the other hand, 
grafts stored by freeze-drying do not survive (Bacsich and Wyburn, 1954).

The purpose of a nerve graft is not to provide a functioning replacement, but a tissue bridge for the regenerating nerve fibres to cross from the central to the peripheral stump. What is asked of a homograft is that it should remain viable until the crossing is complete. Once the gap is bridged by the regenerating fibres the support of the graft tissue appears to be no longer essential. Sheath cells can spread from the central stump and the host connective tissue elements replace the fibrous framework of the reconstituted nerve. Nerve homografts are equal to this limited task in rabbits (Sanders and Young, 1942) and in cats (Bentley and Hill, 1936), but despite a spate of experimental work during and immediately after the recent war, there is no reliable report of a successful human nerve homograft. Perhaps because of this dismal record there is today only a trickle of work on nerve grafts, and yet it should not be an insuperable problem to keep the homograft alive for a limited time. The explanation that the failure of the human nerve homograft is merely a question of relative size-a larger gap, a longer homograft, more difficult to vascularize, and a greater length of regenerating nerve fibresis not wholly satisfactory. Quite large human nerve autografts ' take' and are repopulated with regenerating fibres (Barnes, Bacsich and Wyburn, 1945a). The tempo of events in an organism is generally geared to the dimensions of the task in space and time, and it is thus doubtful if it is altogether justified to assume that the rate of regeneration of nerve fibres is the same for man and the rabbit.

In all the human nerve homografts which have been examined histologically, the regenerating fibres have penetrated some distance into the graft which here retains the structural framework of a nerve. It has been suggested (Sanders, I954) that the length of graft innervated is correlated to the total size of the graft, indicating a dosage effect - the longer the graft the bigger the antigen dose and so the more rapid the onset of the immune reaction. Out of a series of eight nerve homografts, three of which were examined histologically (Barnes, Bacsich, Wyburn and Kerr, 1945b), the proportions were- $25 \mathrm{~mm}$. in $18-\mathrm{cm}$. graft, $12 \mathrm{~mm}$. in a $9-\mathrm{cm}$. graft, and $15 \mathrm{~mm}$. in a $7-\mathrm{cm}$. graft. There are likely to be many variables in individual host reactions, the most significant the genetic rather than the size factor. It is agreed that there is complete replacement of graft by host tissue elements, but what is interesting is that the structural architecture of the non-innervated part of the graft is retained for a long time. In our series, the fibrous framework of a typical nerve was recognizable after a year, although some of the bundles had a necrotic centre and others were partially filled with a cellular connective tissue After 955 days there was no longer any fascicular. organization, only a homogeneous fibrous mass $\overrightarrow{\vec{B}}$ Obviously a ' ghost' skeleton of the graft survived? the immediate homograft reaction and organized the replacing host connective tissue in the first instance. One incidental observation emerging from nerve-graft work is the latent regenerative capacity of neurons. In our series, fibres re $\frac{0}{\mathrm{c}}$ generated from the central stump after two years. Presumably, isolation from peripheral or muscular connection does not necessarily mean the death of the neuron, and the viable nerve cell can always regenerate its processes. In what way the mechanio cal stimulus of freshening a central stump stirs up. the distant nerve cell is not known.

There is, obviously, worthwhile work still to be done in nerve homografts, particularly in respect of the pre-treatment of the graft.

The bone homograft, whether implanted intoo bone, muscle, or intraocularly, dies and can be recovered as a sequestrum up to a year or later. The behaviour of the bone graft is unique in two ways The graft never takes. Examined within a fews days the cortical lacunae are empty both in auto $-\vec{c}$ grafts and homografts, but in the homograft thस्षु is no sign of living bone cells, whereas in the aumigraft there are living bone cells subperiosteally apdo lining haversian canals and marrow spacess (Hutchison, 1952). By 14 days these cells are⿳亠丷⿵冂丶 active in new bone formation, while the homografto is a sequestrum. Secondly, bone is the only trans- plant which as autograft or homograft can induceo the host tissue to reproduce the grafted tissue. Host osteogenesis commences about ro days after an implant of homogeneous bone into muscle and. ceases, in rabbits at any rate, after 42 days. In? one experiment when the bone homograft was extruded after three days there was new host bone 3 . at the graft site examined two weeks later (Wyburni and Bacsich, 1956). The use of the bone graft, $\frac{0}{3}$ autograft or homograft, is mainly as a stimulus to new bone formation by the host tissues, and? maybe in future the answer to bone loss and repair will not be the bone graft, but the local induction of new bone formation. As previously noted (Wyburn, I957), certain general conclusions aboutn the induction of host osteogenesis by bone homo T్స grafts can be stated:-

(I) The inductive factor or factors is not specific as it is effective although delayed in homogeneous transplants;

(2) Induction is not exclusively the function of bone cells, as the cells of homogeneous grafts die

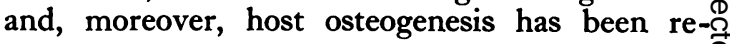


ported with frozen grafts after an interval of 30 days ;

(3) The more immediate and greater inductive response to fresh autogenous grafts suggests a quantitative or qualitative difference in inductive capacity, probably related to the presence of living osteoblasts.

There are, as is well known, many conditions, experimental, pathological, other than bone grafting that can induce osteogenesis not only in bone but in the soft tissues. Over the years there have been a great many theories as to the nature of the osteogenetic stimulus and we still await the right one.

In this connection, recent work by Sobel (1955) gives promise of a new starting point for an experimental approach to osteogenesis. Sobel used the technique of reversible in vitro calcification to demonstrate that the first step in mineralization is the combination of $\mathrm{Ca}^{++}$with some constituent in the calcifiable tissue. He showed that other ions (e.g. strontium) can compete with the calcium ions in the calcifying fluid, and by combining reversibly with this substance can prevent calcification, i.e. can inactivate the tissue. $\mathrm{Re}$-activation of the calcifiable tissue is a function of the ratio of activator to inactivator ions, Text Fig. I. The mineral element of bone, small crystals of hydroxyapatite a few hundred Angstrom units in length are first deposited in ossifying tissue around the repeating bands of the collagen fibres. There is some evidence that the mucopolysaccharide, chondroitin sulphate, is an integral part of the calcifying mechanism. Sulphur-containing mucopolysaccharides appear wherever calcification occurs in normal or abnormal situations. Calcification in vitro of rachitic cartilage is inhibited by toluidine blue which competes with $\mathrm{Ca}^{++}$in the same way as inactivator ions, and so in this case a specific target-the chondroitin sulphate can be assumed to be the calcifying factor. Moreover, $\mathrm{Ca}^{++}$up to a certain concentration causes a change in the polymerization of the chondroitin sulphate complex so that metachromatically it becomes more active.

Sobel suggests that the significant event in the formation of a calcifiable tissue is an altered polymerization which promotes a complex of chondroitin sulphate with collagen in a critical configuration. Given the necessary calcium and phosphate ions in the circulating fluids, this complex acts as a template and provides a possible mechanism for the epitactic (seeding) growth of bone crystals. The next step is to experiment with complexes obtained by condensing chondroitin sulphate from different varieties of collagen and to test them for mineralization by the method of in vitro calcification.
It may be that with the homograft problem, as with the problem of malignant disease, or with the still more intractable enigma, the translation of nerve impulses into conscious sensations, we have reached a barrier and require a new set of concepts before we can break through, just as Pasteur's microbes, Müller's mutations, and the physicist's non-conservation of parity have in their turn broken through to new frontiers. The lessons of history encourage the conviction that sooner or later the homografter will achieve his breakthrough to a successful solution of the problem-a success that will rank along with insulin and penicillin as one of the great advances in medicine.

\section{BIBLIOGRAPHY}

ADEYMO, O., and WYBURN, G. M. (1957), Trans. Bull., 4, 152. ALEXANDER, S. (1957), Brit. F. plast. Surg., 10, I, 36.

ALGIRE, G. H., WEAVER, J. M., and PREHN, R. T. (1957), Ann. N.Y. Acad. Sci., 64, roog.

BACSICH, P., and WYBURN, G. M. (1947), Proc. roy. Soc. Edinb. $B, 72,32$ I.

BACSICH, P., and WYBURN, G. M. (1954), Trans. Bull., 1, 5, 199. BACSICH, P., and WYBURN, G. M. (1955), Ibid., 2, 2, 44 .

BACSICH, P., and WYBURN, G. M. (I955), Ibid., 2, 4, 144.

BARNES, R., BACSICH, P., and WYBURN, G. M. (I945a), Brit. $\mathcal{F}$. Surg., 32, 130.

BARNES, R., BACSICH, P., WYBURN, G. M., and KERR, A. S. (1945b), Ibid., 34, 34 .

BARNES, D. W. H., FORD, C. E., ILBERY, G. L. T., and LOUTIT, J. F. (1958), Trans. Bull., 53, I0I.

BENTLEY, F. H., and HILL, M. (1936), Brit. F. Surg., 24, 368. BILLINGHAM, R. E., KROHN, P. L., and MEDAWAR, P. B. (195 I), Brit. med. $\mathscr{F}$., i, I 157 .

BILLINGHAM, R. E., BRENT, L., and MEDAWAR, P. B. (I953), Nature (Lond.), 172, 603 .

BILLINGHAM, R. E., BRENT, L., and MEDAWAR, P. B. (1956), Philos. Trans. B, 666, 239.

COUPLAND, R. E. (1957), f. Endocr., 15, 2, 162.

CRAIGMYLE, M. B. L. (1955), Brit. F. plast. Surg., 8, 2, 93.

CRAIGMYLE, M. B. L. (1958a), F. Anat. (Lond.), 92, 174.

CRAIGMYLE, M. B. L. (1958b), Ibid., 92, 346.

CURRAN, R. C., and GIBSON, T. (1956), Proc. roy. Soc. B, 144, 572.

FORD, C. E., HAMILTON, J. L., BARNES, D. W. H., and LÓUTiT, J. F. (1956), Nature (Lond.), 177, 452.

GALliaRD, P. J. (I954), Ciba Foundation Symposium, 'The Preservation and Transplantation of Normal Tissues,' J. \& A. Churchill, London, p. roo.

GIBSON, T., and MEDAWAR, P. B. (1943), F. Anat. (Lond.), 77, 299.

GIBSON, T., DAVIS, W. B., and CURRAN, R. C. (1958), Brit.' '. plast. Surg., 11,3 , 177.

HUTCHISON, J., TOUGH, J. S., and WYBURN, G. M. (1949), Ibid., 2, 82.

HUTCHISON, J. (1952), Ibid., 39, I 58, 2.

KALISS, N. (1955), Ann. N.Y. Acad. Sci., 59, 385.

LOEB, L. (1945), 'The Biological Basis of Individuality,' C. Thomas, Baltimore.

LOVELOCK, J. W. (1953), Biochim. biophys. Acta.

LOVELOCK, J. W. (1954), 'In Preservation and Transplantation of Normal Tissues,' Ciba Foundation Symposium, J. \& A. Churchill, London.

MAUMENEE, A. E. (1953), Trans. Bull., r, 117.

NELKEN, E., MICHAELSON, I. C., and GUREVITCH (1958), Ibid., $5, \mathrm{I}, 9$.

NUNGSTER, W. J., JOURDONAIS, L. F., and WOLF, A. H. (1936), F. infect. Dis., 59, 2.

PARKES, A. S. (1957), 'A Discussion on Viabilitv of Mammalian Cells and 'Tissues after Freezing,' Proc. roy. Soc. B, 147, 520.

POLGE, C., SMITH, A. U., and PARKES, A. S. (1949), Nature (Lond.), 164, 666.

ROB, C. (1954), Lancet, August 7, 255.

ROB, C., and EASTCOTT, H. H. G. (1954), Ciba Foundation Svmposium, 'The Preservation and Transplantation of Normal Tissues, J.'\& A. Churchill, London, p. 190.

Bibliography continued on page 155 
The literature contains many reports of cases in which a symptom-free interval between injury and strangulation of a traumatic diaphragmatic hernia can be measured in months. The latent period in this case was over 33 years. Mild bowel symptoms culminating in acute intestinal obstruction suggested a diagnosis of carcinoma of the colon. The correct diagnosis was not made because the small scars on the chest wall were not deemed relevant; because the shadow of the metallic fragment in the abdominal radiograph was likewise disregarded; and because the original injury was looked upon as an unimportant fact of remote history.

\section{Summary}

A case of traumatic herniation of the left hemidiaphragm due to penetrating injury is described.
Following wounding in 1918 there was a long interval without symptoms.

Acute obstruction of the colon developed $33 \frac{1}{2}$ years later preceded only by a few months of mild premonitory symptoms.

\section{Acknowledgments}

I wish to thank Mr. Ralph H. Gardiner for permission to report this case, and the Chief Medical Officer of the Ministry of Pensions for confirmation of essential dates and for permission for publication.

\section{BIBLIOGRAPHY}

BELCHER, J. R. (1956), personal communication.

CARTER, B. N., and GIUSEFFI, J. (1948), Ann. Surg., 128, 2 10. HAVARD, C., and PROBERT, W. R., to be published.

WINDSOR, H. M. (1957), Brit. med. F., i, 1344 .

Bibliography continued from page I 37-The Homograft, C. M. Wyburn

SANDERS, F. K., and YOUNG, J. Z. (1942), f. Anat. (Lond.), 76, 143 .

SANDERS, F. K. (I954), 'Preservation and Transplantation of Normal Tissues,' Ciba Foundation Symposium, J. \& A Churchill, London.

SCOTHORNE, R. J., and TOUGH, J. S. (1952), Brit. F. plast. Surg., 5, I6r.

SCOTHORNE, R. J., and McGREGOR, I. A. (1953), f. Anat. (Lond.), 87, 379 .

SCOTHORNE, R. J., and McGREGOR, I. A. (r955), Ibid., 89, 283. SCOTHORNE, R. J. (1956), Ibid., 93, 4r 7.

SCOTHORNE, R. J. (1958), Ann. N.Y. Acad. Sci., 73, 673.

SINGER, M. (1958), Sci. Amer., 199, 4, 79.

SNELL, J. D. (1952), Cancer Res., 12, 543.

SOBEL, A. E. (1955), Ann. N.Y. Acad. Sci., 60, 7r 3.

WYBURN, G. M., and BACSICH, P. (1955), Brit. F. plast. Surg., 8, I77.

WYBURN, G. M., and BACSICH, P. (1956a), Trans. Bull., 3, I, 3. WYBURN, G. M., and BACSICH, P. (1956b), Ibid., 3, 3, 79.

WYBURN, G. M. (1 957), f. roy. Coll. Surg. (Edin.), 2, 315.

WOODRUFF, M. F. A. (1957), Ann. N.Y. Acad. Sci., 64, ror4.

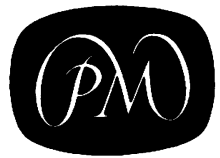

\section{THE NEUROLOGIC EXAMINATION}

\section{RUSSELL N. DEJONG}

Professor of Neurology, University of Michigan Medical School

The second edition of a well-known work, completely revised in the light of modern research, clinical experience and methods of therapy. The book is a complete coverage of the structure and functioning of the normal as well as the diseased nervous system.

1096 pages 300 illus. $€ 700$ net

\section{ILLUSTRATED PRE-OPERATIVE AND POST-OPERATIVE CARE}

PHILIP THOREK, M.D., F.A.C.S., F.I.C.S. Drawings by CARL LINDEN

A clear, concise and dogmatic little book. Of the previous book by Thorek and Linden, Surgical Diagnosis, the B.M.J. said "The author has a quite exceptional power of compressing all the essentials of description in the briefest possible space; the artist has an equal power ... It is a very rare and happy combination."

100 pages 60 illus. 30s. net

PITMAN MEDICAI PUBLISHING Co. Ltd. 39 PARKER STREET, LONDON, W.C.2

\section{RECENTLY PUBLISHED}

\section{Modern Treatment Yearbook 1959}

\section{Edited by}

SIR CECIL WAKELEY, Bt., K.B.E., C.B., LL.D., M.Ch., D.Sc., F.R.C.S., F.R.S.E., F.R.S.A., F.A.C.S., F.R.A.C.S.

Specially written to keep the general practitioner informed on the latest therapeutic methods and on the practical applications of the latest research. Thirty-one articles on many of the conditions commonly encountered by general practitioners in their daily work, with the accepted methods of diagnosis and treatment, each thoroughly tested and the result of hospital experience.

25th issue 320 pages. 16 plates and many other illustrations. 30s. Postage 1s. 9d.

Published for the Medical Press by

BAILLIERE, TINDALL \& COX 7 \& 8 Henrietta Street, London W.C.2 